NASA Technical Memorandum 106523

AIAA-94-1119

\title{
The Telemedicine Spacebridge Project- A Joint U.S./Russian Venture in Long Distance Medicine Via Satellite
}

John E. Zuzek, Michael A. Cauley, and James E. Hollansworth Lewis Research Center

Cleveland, Ohio

Prepared for the

15th International Communications Satellite Systems Conference sponsored by the American Institute of Aeronautics and Astronautics San Diego, California, February 28-March 3, 1994

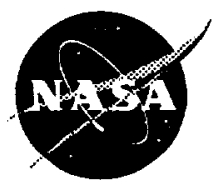

National Aeronautics and Space Administration

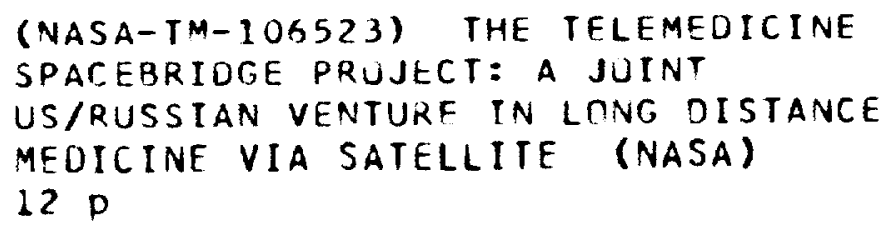

N94-27427

Unclas

$63 / 170000331$ 


\title{
THE TELEMEDICINE SPACEBRIDGE PROJECT - A JOINT U.S./RUSSIAN VENTURE IN LONG DISTANCE MEDICINE VIA SATELLITE
}

\author{
John E. Zuzek', Michael A. Cauley, and James E. Hollansworth \\ NASA Lewis Research Center \\ Cleveland, $\mathrm{OH} 44135$
}

\begin{abstract}
1. Abstract
The Telemedicine Spacebridge Demonstration Project is a joint U.S./Russian program whose purpose is to further the application of telemedicine both internationally, domestically, and in space. The system has been set up to use a Russian satellite over the Atlantic Ocean and a U.S. domestic satellite to allow physicians a two-way video and audio link between various sites of medical centers in the United States and the Central Hospital in Moscow, Russia. This paper contains a description of the project background, the Spacebridge system, the individual pieces of the system, and the operational experience gained thusfar in the project.
\end{abstract}

\section{Introduction}

An emerging application of telecommunications technology is telemedicine. Telemedicine is defined as the use of telecommunications to aid in the medical process through such things as consultation, telediagnosis, teleradiology and telepathology to name just a few of the applications. The Telemedicine Spacebridge uses satellites and terrestrial telephone links to connect Moscow, Russia with several U.S. medical centers.

NASA first became involved in satellite telemedicine in the 1970's when a NASA satellite was used for medical consultation and health care delivery to remote sites in Alaska. In 1989, NASA initiated a telemedicine Spacebridge program to aid victims of the earthquake in Armenia, U.S.S.R.
During the Bush-Gorbachev Summit meeting held on July $30-31,1991$, agreements were reached in areas of the civil space program and disaster assistance. A Memorandum of Understanding (MOU) was signed on disaster assistance. This bilateral umbrella agreement has among its goals "to increase the technical capabilities of both sides to respond to both natural and man-made disasters" and "to benefit from the capabilities and involvement of international and non-governmental organizations". In addition, the U.S. and U.S.S.R. also agreed to expand civil space cooperation by flying a U.S. astronaut on the Mir Space Station and a Soviet cosmonaut on a U.S. Space Shuttle mission. One of the major reasons for the exchange of flights is to conduct Life Sciences research of mutual interest. This Life Sciences research would advance current efforts to standardize in-flight medical procedures which would improve comparability of data taken by each side.

Earlier U.S.-U.S.S.R. agreements developed by the Joint Working Group (JWG) on Space Biology and Medicine dictated that an approach for implementing a Telemedicine Spacebridge be studied and developed using the Soviet WSDRN (Western Satellite Data Relay Network)(also known as "Loutch") geostationary communications satellite located at $16^{\circ}$ West longitude. These studies were performed and completed by October of 1991. The basic feasibility of the Telemedicine Spacebridge was verified in a brief demonstration in conjunction with the International Telemedicine Conference in Bethesda, Maryland on December 10-11 of 1991. This demonstration was performed using the WSDRN satellite and a prototype SDRN

- Associate Member AIAA 
(Satellite Data Relay Network) earth station loaned to the U.S. by the Soviets that acted as a gateway at NASA Lewis Research Center in Cleveland, Ohio, and a domestic satellite to link the conference attendees in Bethesda with a studio in Moscow, Russia. Much of 1992 was spent acquiring and setting up a permanent gateway earth station at NASA Lewis Research Center as well as addressing many of the bureaucratic aspects of this international project. The U.S. and Russian governments have entered into agreements and committed to the Telemedicine Spacebridge Demonstration Project which began regular operation on September 10,1993 and will continue its initial operational phase through May 20, 1994.

\section{System Overview}

The Telemedicine Spacebridge Demonstration Project provides a two way video link between medical specialists at participating medical institutions in the U.S. and their counterparts in the Russian Republic. The experimental Spacebridge link is used to address such topics as disaster medicine, routine patient consultation, medical evaluation, medical information exchange (i.e. patient information, and relevant literature), space medicine issues, and other telemedicine applications.

Two earth stations are located at NASA's Lewis Research Center in Cleveland, Ohio. One is a domestic Ku-band earth station and the other a Russian earth station for use with the Russian WSDRN satellite located at $16^{\circ}$ West longitude. The two stations, coupled with video standards converters and encryption equipment, form a "gateway facility" to link Moscow, Russia to various participating U.S. medical institutions via a double satellite "hop". The participating medical institutions in the U.S. are the Uniformed Service University of Health Sciences in bethesda, MD, the University of Texas in Houston, TX, the LDS Hospital in Salt Lake City, UT, and Fairfax Hospital in Fairfax, Virginia. Additionally, NASA Johnson Space Center will participate in sessions on Space Medicine via the University of Texas. Only one U.S. site uplinks during each session while the rest of the domestic sites participate by terrestrial audio links as secondary sites. The system overview is shown in figure 1.

\subsection{Russian WSDRN or "Loutch" Satellite}

The Russian government is making available to the demonstration project, satellite time on the WSDRN (Western Satellite Data Relay Network) satellite which is depicted in figure 2. The WSDRN or "Loutch" satellite is the key segment of the overall Spacebridge system. This satellite was designed and launched by the Russian government to support the Russian space program. The satellite is normally used for two-way video communications with the MIR orbiting space station. It has a unique communications configuration and antenna pointing capabilities that allow direct communications with Mir from Moscow. Additionally, these unique features and its position at $16^{\circ}$ West longitude allow the configuration of a link between NASA Lewis Research Center in Cleveland, Ohio and Moscow, Russia for the Telemedicine Project. There are also other SDRN satellites spaced in orbit to form a complete constellation which acts as a data relay network for Russian space operations. The WSDRN satellite was chosen due to its orbital location in the geostationary orbit and video communications capabilities. Due to the $16^{\circ}$ West longitude position, the elevation angle at the Cleveland gateway is approximately $9.4^{\circ}$ while the elevation angle at the Moscow Central or Hub Station is about $11.6^{\circ}$ as shown by the visibility contours in figure 3 .

The Ku-band transponder on board the WSDRN satellite is of a different design than used by typical U.S. domsats. With U.S. domsats, the uplink and downlink coverage areas are nearly identical. This means an uplink earth station located within the coverage area of the satellite probably can receive their own downlink signal. This is not true for the WSDRN satellite.

The SDRN transponder can be thought of as two separate transponders using two different steerable antennas. Each antenna is connected to one receiver and one transmitter. The output signal from the receiver connected to one antenna is sent to the transmitter connected to the other antenna. Using this satellite architecture, the Cleveland SDRN earth station can send signals to the Moscow "Central" earth station, but the Cleveland SDRN earth station cannot receive it's own downlink signal. The Cleveland SDRN earth station can only receive signals from the Moscow "Central" earth station. The same is true for the 
Moscow to Cleveland path. This configuration is ideal when one of the satellites antenna's must track a moving earth station such as the one located on the MIR space station. Technical specifications for the WSDRN satellite are contained in figure 4.

The video relayed through the WSDRN satelite will not be encrypted because the risk of unauthorized reception is negligible for the following reasons: (1) The WSDRN satellite is only visible to the east coast of the U.S.; (2) TVRO equipment for the frequencies used by the WSDRN satelite is not available; (3) The video signals will use the PAL video standard which is incompatible with the NTSC video standard used in the U.S.

\subsection{U.S. Gateway Station}

NASA's Lewis Research Center located in Cleveland Ohio acts as the communications "gateway" station during operation of the Spacebridge. Because a single satellite in geosynchronous orbit cannot cover the entire geographical area containing all of the participating medical centers in both the United States and Russia, two geosynchronous satellites are connected by the "gateway" station. The Russian WSDRN satellite provides the Moscow to Cleveland satellite link, and a GTE Spacenet GSTAR II domestic Ku-band satellite provides the satellite link between Cleveland and each participating U.S. medical center .

For this experiment, two domestic Ku-band transponders and the Russian WSDRN satellite are used. Recall that figure 1 is an overview of the system. Note that the U.S. medical centers can only communicate through the GSTAR II satellite and using dial-up telephone lines. The Moscow studio can only communicate through the WSDRN satellite. NASA Lewis Research Center acts as the gateway or "hub" of the Spacebridge system. All audio and video signals are routed through the Cleveland facility. For the video signals, the output of the SDRN earth station receiver is routed through a video standards converter to the domestic earth station transmitter for transmission to all U.S. domestic sites and the domestic earth station received signal is routed through a second video standards converter to the SDRN earth station transmitter for retransmission to Moscow. The standards converters are used to convert between the Phase Alternative Line (PAL) video standard used in Western Europe and the National Television Standards Committee (NTSC) video standard used here in the U.S. Specific details of the audio system are significantly more complicated and are beyond the scope of this paper. The system accepts a total of six inputs and routes them to the proper destinations taking into account the appropriate audio delays.

\subsection{Domestic Ku-band Earth Station}

During July 1992, NASA Lewis Research Center installed a commercial domestic Ku-band transceiving earth station to support the demonstration project. This station is licensed through the Interdepartmental Radio Advisory Committee (IRAC) and has been given the call sign NA2XGZ. The current expiration date of the license is February 28, 1997. Technical details for this earth station are provided in table 1 . This earth station is licensed for use with any U.S. domestic Ku-band satelite located between $65^{\circ}$ and $143^{\circ}$ West. The 5 meter antenna and 280 Watt maximum transmitter power provide an excellent video signal for U.S. distribution of the Russian transmissions. Similarly, the $0.7 \mathrm{~dB}$ noise figure of the LNB along with the high gain antenna allow for clean reception and retransmission of the signals originating at the U.S. medical centers. These specifications allow for a nearly transparent gateway station with respect to video picture quality.

All video carried over the U.S. domestic satellites will be encrypted to protect patient confidentiality. NASA has purchased the Macrovision VES-230-TD video scrambling system for each of the U.S. medical centers and for the gateway station. Although this equipment does provide absolute security of transmissions, it does provide adequate confidentiality for the Spacebridge purposes.

\subsection{Russian SDRN Earth Station}

The SDRN earth station can communicate with the WSDRN satellite to transmit and receive full bandwidth video with companion audio signals. The Russian government had previously delivered and installed a prototype Russian earth station at NASA Lewis Research Center in Cleveland, Ohio for use with the WSDRN satellite. This earth station along with leased domestic earth terminals was used to link Moscow, Russia with the Interna- 
tional Telemedicine Conference in Bethesda, Maryland on December 10-11, 1991. The purpose of this activity was to demonstrate the feasibility of such a link for telemedicine purposes. The prototype Russian earth station was later relocated and will be sent back to Russia. A new Russian SDRN earth station was delivered and installed in Cleveland in late August of 1993 . This earth station is a greatly improved version of the prototype earth station previously delivered. The technical specifications of the new SDRN earth station are presented in table 2.

The new SDRN earth station is known as the Stationary Transportable Transceiving station (TTS)and is part of a system intended to gather and transmit "hot" video news using the Loutch geostationary communications satellite. It was designed to broadcast the television reports from mass media sites of interest through the satellite to the Moscow Hub Station. The SDRN TT-S provides the transmission and reception of one video, two high fidelity audio and four orderwire channels in the $15 / 13 \mathrm{GHz}$ band. The frequency band in question posed a problem in the U.S. in that it is in somewhat sensitive government bands. Special permission was requested and received to transmit and receive on an occasional and experimental basis.

Although the SDRN earth station is somewhat small and low power by common broadcast quality video standards, it is adequate to achieve approximately $50 \mathrm{~dB}$ signal-to-noise ratios for the video signals. The block diagram of the SDRN earth station is given in figure 5 .

\subsection{U.S. Domestic Satellite - GTE GStar II}

NASA, Lewis Research Center (LeRC) issued an Request for Procurement (RFP) for two domestic $36 \mathrm{MHz}$ Ku-band transponders and one Ku-band mobile uplink/downlink truck on a scheduled basis. The transponders are used to interconnect the Lewis Research Center with participating university medical centers as part of the Telemedicine Spacebridge Demonstration Project to support twoway, full motion video with companion hi-fidelity audio channels. The uplink / downlink truck is to provide participating university medical centers with connectivity to the domestic transponders.

GTE Spacenet Corporation was awarded the contract on March 25, 1993, to provide transponder capacity on GSTAR || located at $125^{\circ}$ West longitude and uplink/downlink truck capability for the duration of this phase of the TMSB Project. This activity currently calls for a total of 16 scheduled and the provision for 16 additional, 4 hour events beginning on September 10, 1993 and occurring approximately every second week thereafter.

If in the event a natural or manmade disaster should occur, plans are in place to maintain 24 hour around the clock operation as needed.

\section{$3.6 \quad$ U.S. Medical Centers}

A total of four U.S. medical centers will be connected to the Spacebridge. During each session, only one U.S. medical center will actively uplink video. This medical center will be designated as the "primary" site for the session. The remaining medical centers will be designated as "secondary" sites and can participate in the session by simultaneously receiving video from Moscow and from the U.S. primary site using two domestic TVRO (TV Receive Only) satellite receivers tuned to two transponders on the commercial domestic Ku-band satellite. Secondary sites can inject their comments into the session using a dial-up telephone line via telephone hybrids from their site to the Cleveland gateway facility.

Medical experts at each of the medical centers will have two video monitors placed in the front of the room. The first monitor will display live video from the Moscow studio. The second monitor will display live video from the "primary" U.S. site. Audio speakers in the room will allow the medical experts to listen to all of the other medical centers. The medical experts can participate in the discussions simply by talking into a microphone located in the room.

\subsection{Uplink/Downlink Transportables}

GTE Spacenet provides uplink/downlink capabilities on a scheduled basis at the following locations:

1. Bethesda, Maryland (Uniformed Services University of the Health Sciences (USUHS))

One Ku-band fully redundant transportable uplink /downlink capable of monitoring its own signal. 
The Bethesda uplink/ downlink is a 2.4 meter RSI antenna with a transmit gain of $53.2 \mathrm{dBi}$ at 14.25 $\mathrm{GHz}$. The transportable uplink/downlink has two MCL 10906 phase-combined, 300 Watt traveling wave tube amplifiers (TWTA's) with harmonic and reject filters, a digital attenuator option, and one input bandpass filter. The antenna system maximum EIRP is $79.9 \mathrm{dBW}$. Two LNR LVE-14 video exciters are also provided.

2. Salt Lake City, Utah (LDS Hospital, University of Utah)

One Ku-band fully redundant transportable uplink /downlink capable of monitoring its own signal. The Salt Lake City uplink/downlink is a 2.4 meter Andrews antenna with a transmit gain of $50.0 \mathrm{dBi}$ at $14.25 \mathrm{GHz}$ and a noise temperature of $38^{\circ} \mathrm{K}$. The transportable uplink has two phase-combined, 300 Watt TWTA's with harmonic and reject filters, a digital attenuator option, and one input bandpass filter. The antenna system maximum EIRP is 74.3 dBW. Two Miter VEL-14-8507 low profile video exciters are also provided.

3. Houston, Texas (University of Texas, Health Science Center)

One Ku-band fully redundant transportable uplink /downlink capable of monitoring its own signal. The Houston uplink is a 2.4 meter antenna. The transportable uplink has two phase-combined, 300 Watt TWTA's with harmonic and reject filters, a digital attenuator option, and one input bandpass filter. The RF equipment has one-for-one hot standby. Two video exciters with high-level RF, video, and audio performance are also provided.

\section{Fairfax, Virginia (Fairfax Hospital)}

Fairfax Hospital presents a unique capability or option that none of the other participants offer. This capability is as follows:

a.) The hospital is hard-wired for transmission of audio and video via a two-way fiber optic link to the Chesapeke and Potomac Telephone Company routing switch. This gives the hospital the option of routing their audio and video traffic terrestrially to another local location, to the Washington Area Teleport, or to a satellite carrier of choice.

b.) The hospital has the additional capability to interface with a Ku-band transportable earth terminal. The Fairfax transportable is a 2.4 meter RSI antenna with a transmit gain of $53.2 \mathrm{dBi}$ at $1425 \mathrm{GHz}$. The transportable uplink/downlink has two MCL 10906 phase-combined, 300 Watt TWTA's with harmonic and reject filters, a digital attenuator option, and one input bandpass filter. Two LNR LVE-14 video exciters are also provided.

\section{Operational Experience}

The total NASA Telemedicine Spacebridge Program is managed by NASA Headquarters Space Life Sciences. The Telemedicine Spacebridge Demonstration Project telecommunications aspects are managed by the Space Electronics Division at the Lewis Research Center in Cleveland, Ohio. To date, the Spacebridge has performed well, despite numerous technical and bureaucratic problems. One major difficulty with scheduling Spacebridge sessions is that the Telemedicine Spacebridge Demonstration Project is a secondary user of the WSDRN satellite. As was mentioned previously, the SDRN system is primarily used to communicate with the Mir Space Station and those communications must obviously take priority over any Spacebridge activities. Occasionally, this secondary user designation can cause havoc in scheduling of Spacebridge sessions. The current schedule of sessions is given in table 3 .

Although the video has been acceptable to date, there have been numerous instances of audio problems. Some of these problems were no doubt exacerbated by the satellite double hop. Precautions were taken to minimize any feedback problems with the audio paths, but with such a complex system, the smallest error such as leaving a live microphone open at the wrong time can cause tremendous problems. Many of these problems were corrected during the pilot sessions using improved room acoustics and better handling of the microphones.

There were some minor video glitches during the telepathology session. These were apparently the result of a problem with the telepathology equipment itself and its conversion of the computer RGB signals to NTSC signals for transmission over the Spacebridge. The same telepathology system in Moscow, Russia did not exhibit such problems. This problem has since been addressed by the 
telepathology equipment experts.

During October of 1993, the storming of the Russian Parliament regrettably resulted in numerous trauma cases. The Spacebridge was used on two separate occasions to hold special trauma sessions where many of these trauma cases were addressed.

\section{Conclusion}

The relative success which NASA has enjoyed with its telemedicine experiences in the past would suggest that this current effort could revolutionize the way medical services are delivered around the world. Furthermore, the life sciences experiences gained by the U.S. and Russian republic through the Telemedicine Spacebridge effort will enhance the capabilities and knowledge for manned space missions for all future spacefaring nations.

\section{Bibliography}

1] Transportable Transceiving Stations, Stationary and Mobile - Log Book", Institute of Space Device Engineering, Moscow, Russia, 1993

2] "Stationary Transportable Transceiving Station (TTS-S) Technical Description", Institute of Space Device Engineering, Moscow, Russia, 1993, EKMH 463336.001 TO

3] Telemedicine Spacebridge - Medical Consultation Utilizing the Russian WSDRN Satellite and a U.S. GTE Spacenet GStar II Domestic Ku-Band Satellite", J.E. Zuzek, M.A. Cauley, and J.E. Hollansworth, NASA Lewis Research Center White Paper, April 20, 1993

4] "Telemedicine Demonstration Project Implementation Plan", NASA Headquarters, Washington, DC, September, 1993

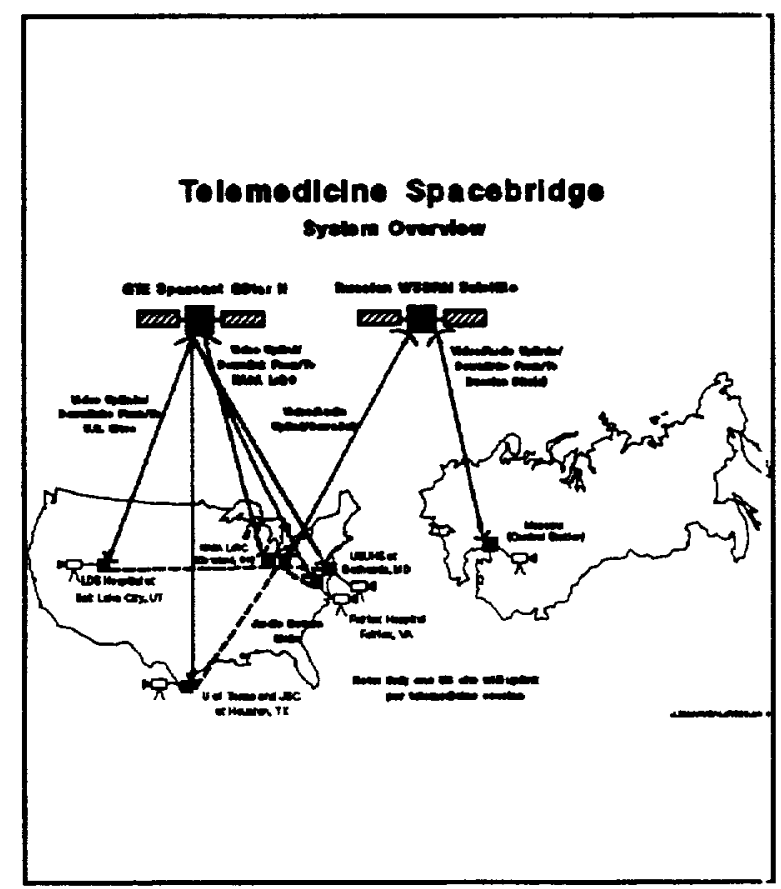

Figure 1 System Overview of the Telemedicine Spacebridge Demonstration Project Network 


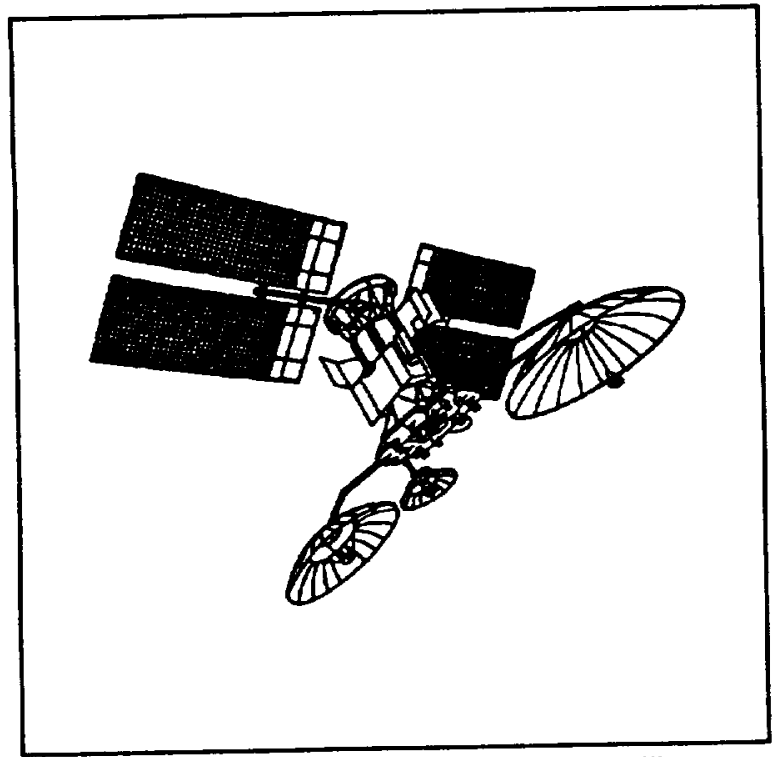

Figure 2 WSDRN or "Loutch" Satellite

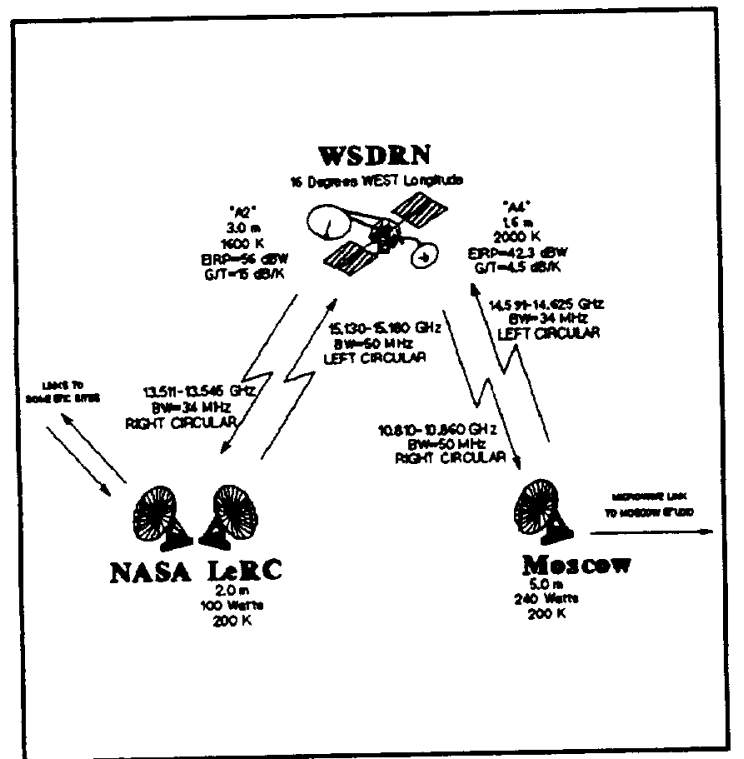

Figure 3 Technical Specifications of the WSDRN Satellite and LeRC Gateway

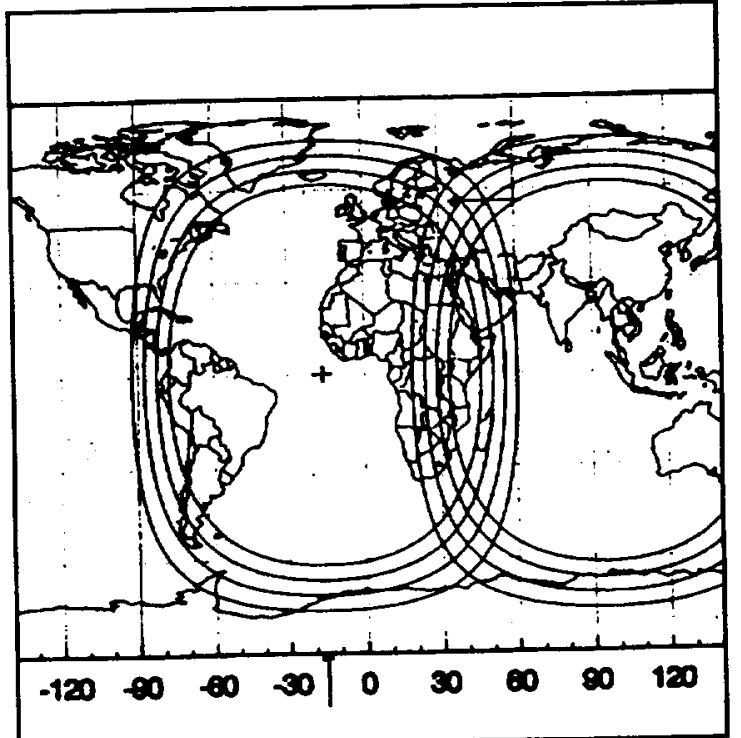

Figure 4 Visibility Contours at $5^{\circ}, 10^{\circ}, 15^{\circ}$, and $20^{\circ}$ for the WSDRN Satellite located at $16^{\circ}$ West

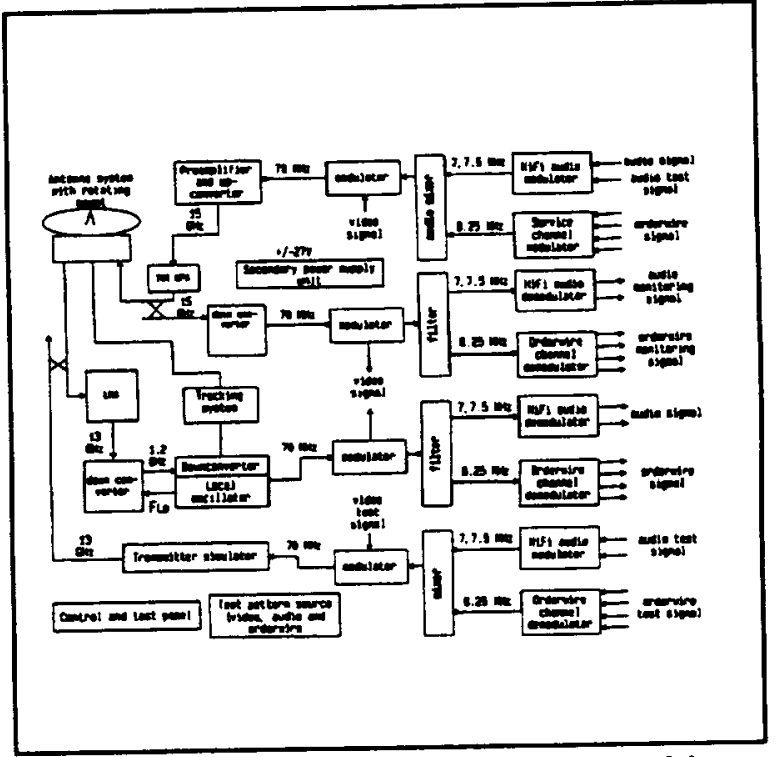

Figure 5 SDRN Transportable Transceiving Station Block Diagram 


\begin{tabular}{|c|c|}
\hline \multicolumn{2}{|l|}{ Antenna } \\
\hline Diameter & 5.0 meters \\
\hline \multirow[t]{2}{*}{ Gain } & $55.0 \mathrm{dBi}\left(\right.$ Uplink) $\left(0.29^{\circ} \varangle 3 \mathrm{~dB}\right)$ \\
\hline & $53.6 \mathrm{dBi}$ (Downlink) $\left(0.34^{\circ} \varangle 3 \mathrm{~dB}\right)$ \\
\hline \multirow[t]{3}{*}{ Pointing } & $180^{\circ}$ Azimuth (southerly coverage only) \\
\hline & $0^{\circ}$ to $90^{\circ}$ Elevation \\
\hline & Several Tracking Modes Including Step Track \\
\hline Polarization & Linear: $-90^{\circ}$ to $+90^{\circ}$ (continuously variable) \\
\hline \multicolumn{2}{|l|}{ Receiver } \\
\hline Receiver Frequency & 11.7 to $12.2 \mathrm{GHz}$ (5 MHz step size) \\
\hline \multirow[t]{3}{*}{ Audio Subcarriers } & $\# 1-5.0$ to $8.5 \mathrm{MHz}$ (5 $\mathrm{kHz}$ step size) \\
\hline & $\# 2-5.0$ to $8.5 \mathrm{MHz}$ (5 kHz step size) \\
\hline & \#3 - 5.0 to $8.5 \mathrm{MHz}$ (5 kHz step size) \\
\hline LNB Noise Figure & $0.7 \mathrm{~dB}\left(50.7^{\circ} \mathrm{K}\right)$ \\
\hline LNB Conversion Gain & $>50 \mathrm{~dB}$ \\
\hline IF Frequency & 950 to $1450 \mathrm{MHz}$ \\
\hline \multicolumn{2}{|l|}{ Transmitter } \\
\hline Transmit Frequency & 14.0 to $14.5 \mathrm{GHz}$ ( $125 \mathrm{kHz}$ step size) \\
\hline \multirow[t]{3}{*}{ Audio Subcarriers } & $\# 1-4.5$ to $8.5 \mathrm{MHz}$ ( $5 \mathrm{kHz}$ step size) \\
\hline & $\# 2-4.5$ to $8.5 \mathrm{MHz}$ (5 kHz step size) \\
\hline & $\# 3-7.1 \mathrm{MHz}$ (for Morse Code ID) \\
\hline Frequency Stability & $\pm 7 \mathrm{ppm}\left(\mathrm{ppm}=1 \times 10^{-6}\right.$, i.e., $\left.100 \mathrm{kHz} @ 14.5 \mathrm{GHz}\right)$ \\
\hline Transmitter Output Power & 280 Watts (at rear of amplifier) \\
\hline
\end{tabular}

Table 1: Technical Specifications of Domestic Ku-band Earth Station 


\begin{tabular}{|c|c|}
\hline \multicolumn{2}{|l|}{ Antenna } \\
\hline Diameter & 2.0 meters \\
\hline \multirow[t]{2}{*}{ Gain } & $45.5 \mathrm{dBi}$ (Uplink) $\left(0.70^{\circ} \varangle 3 \mathrm{~dB}\right)$ \\
\hline & $45.0 \mathrm{dBi}$ (Downlink) $\left(0.78^{\circ} \varangle 3 \mathrm{~dB}\right)$ \\
\hline \multirow[t]{2}{*}{ Pointing } & $\pm 85^{\circ}$ Azimuth (from selected direction) \\
\hline & $10^{\circ}$ up to $85^{\circ}$ Elevation \\
\hline \multirow[t]{2}{*}{ Polarization } & Transmit - Left Circular \\
\hline & Receive - Right Circular \\
\hline \multicolumn{2}{|l|}{ Receiver } \\
\hline Receiver Frequency & 13.508 to $13.548 \mathrm{GHz}$ \\
\hline \multirow[t]{2}{*}{ Audio Channels } & $\# 1-0.04$ to $15 \mathrm{kHz}$ ( 2 mono or 1 stereo) \\
\hline & $\# 2-\# 5-0.3$ to $3.4 \mathrm{kHz}$ (orderwire channels) \\
\hline LNB Noise Temperature & does not exceed $200^{\circ} \mathrm{K}$ \\
\hline $\mathrm{G} / \mathrm{T}$ equivalent & $19.7 \mathrm{~dB} / \mathrm{K}$ \\
\hline IF Frequency & 1206 to $1240 \mathrm{MHz}$ \\
\hline \multicolumn{2}{|l|}{ Transmitter } \\
\hline Transmit Frequency & 15.135 to $15.175 \mathrm{GHz}$ \\
\hline \multirow[t]{2}{*}{ Audio Subcarriers } & $\# 1-0.04$ to $15 \mathrm{kHz}$ (2 mono or 1 stereo) \\
\hline & \#2 - \#5 - 0.3 to $3.4 \mathrm{kHz}$ (orderwire channels) \\
\hline Transmitter Output Power & 50 Watts \\
\hline
\end{tabular}

Table 2: $\quad$ Technical Specifications of the Russian SDRN Earth Station 


\begin{tabular}{|c|c|c|c|}
\hline Session & Date & Primary Site & Session Description \\
\hline \multicolumn{4}{|c|}{ Pilot Sessions } \\
\hline$T$ & 09/02/93 & All sites & Technical Checkout \\
\hline A & $09 / 10 / 93$ & USUHS & $\begin{array}{l}\text { Oncological Disease Resulting From Radia- } \\
\text { tion Exposure }\end{array}$ \\
\hline $\mathbf{B}$ & $09 / 24 / 93$ & USUHS & Pathology/Radiology \\
\hline $\mathbf{C}$ & $10 / 08 / 93$ & UT & Emergency Medicine/Trauma \\
\hline \multicolumn{4}{|c|}{ Operational Sessions } \\
\hline 1 & $10 / 21 / 93$ & LDS & Emergency Medicine/Trauma \\
\hline 2 & $11 / 05 / 93$ & U.S. Senate & Inaugural Session \\
\hline 3 & $11 / 19 / 93$ & LDS & Esophageal and Gastrointestinal Surgery \\
\hline 4 & $12 / 03 / 93$ & LDS & Cardiovascular Surgery \\
\hline 5 & $12 / 17 / 93$ & UT & Cardiology \\
\hline 6 & $01 / 14 / 94$ & UT & Pre-Hospital Care/Ambulance \\
\hline 7 & $01 / 28 / 94$ & JSC (UT) & Space Medicine \\
\hline 8 & 02/04/94 & Fairfax & Orthopedic/Trauma Care \\
\hline 9 & 02/18/94 & Fairfax & Transplantation Medicine \\
\hline $9 A$ & $02 / 25 / 94$ & UT & Plastic Surgery \\
\hline 10 & 03/04/94 & UT & Medical Oncology \\
\hline 11 & $03 / 18 / 94$ & LDS & Acute Neurological Disorders \\
\hline $11 \mathrm{~A}$ & $03 / 25 / 94$ & JSC (UT) & Space Medicine Simulations \\
\hline 12 & $04 / 01 / 94$ & LDS & Infectious Diseases \\
\hline 13 & $04 / 15 / 94$ & JSC (UT) & Hyperbaric Medicine \\
\hline 14 & $04 / 29 / 94$ & USUHS & Biorhythm Approaches In Medicine \\
\hline 15 & 05/06/94 & USUHS & Urology \\
\hline 16 & $05 / 20 / 94$ & USUHS & Summary Session/Lessons Learned \\
\hline
\end{tabular}

Table 3: $\quad$ Telemedicine Spacebridge Demonstration Project Session Schedule 
Public reporting burden for this collection of information is estimated to average 1 hour per response, inciuding the time for reviewing instructions, searching existing data sources, gathering and maintaining the data needed and completing and reviewing the collection of information. Send comments regarding this burden estimate or any other aspect of this collection of inlomation including sugestions for reducing this burden, to Washington Headquanters Services, Directorate for Information Operations and Reports. 1215 Jeflerson Davis Highway, Suite 1204, Arlington, VA 22202-4302, and to the Office of Management and Budget, Paperwork Reduction Project (0704-0188). Washington, DC 20503.

\begin{tabular}{|l|c|c|}
\hline 1. AGENCY USE ONLY (Leave Dlank) & $\begin{array}{c}\text { 2. REPORT DATE } \\
\text { March } 1994\end{array}$ & $\begin{array}{r}\text { 3. REPORT TYPE AND DATES COVERED } \\
\text { Technical Memorandum }\end{array}$ \\
\hline
\end{tabular}

\section{TITLE AND SUBTITLE}

The Telemedicine Spacebridge Project-A Joint U.S./Russian Venture

in Long Distance Medicine Via Satellite

\section{AUTHOR(S)}

John E. Zuzek, Michael A. Cauley, and James E. Hollansworth

\section{PERFORMING ORGANIZATION NAME(S) AND ADDRESS(ES)}

National Aeronautics and Space Administration

Lewis Research Center

Cleveland, Ohio 44135-3191

9. SPONSORING/MONITORING AGENCY NAME(S) AND ADDRESS(ES)

National Aeronautics and Space Administration

Washington, D.C. 20546-0001
5. FUNDING NUMBERS

WU-106-70-00

8. PERFORMING ORGANIZATION REPORT NUMBER

E-8646

10. SPONSORINGMONITORING AGENCY REPORT NUMBER

NASA TM-106523

AIAA-94-1119

11. SUPPLEMENTARY NOTES

Prepared for the 15th International Communications Satellite Systems Conference sponsored by the American Institute of Aeronautics and Astronautics, San Diego, California, February 28-March 3, 1994. Responsible person, John E. Zuzek, organization code 5610, (216) 433-3469.

12a. DISTRIBUTIONAVAILABILITY STATEMENT

12b. DISTRIBUTION CODE

Unclassified - Unlimited

Subject Categories 17, 32, and 51

\section{ABSTRACT (Maximum 200 words)}

The Telemedicine Spacebridge Demonstration Project is a joint U.S./Russian program whose purpose is to further the application of telemedicine both internationally, domestically, and in space. The system has been set up to use a Russian satellite over the Atlantic Ocean and a U.S. domestic satellite to allow physicians a twoway video and audio link between various sites of medical centers in the United States and the Central Hospital in Moscow, Russia. This paper contains a description of the project background, the Spacebridge system, the individual pieces of the system, and the operational experience gained thusfar in the project.

\section{SUBJECT TERMS} 15. NUMBER OF PAGES

Satellite communications; Telemedicine; Russian satellite

17. SECURITY CLASSIFICATION
OF REPORT
Unclassified

NSN 7540-01-280-5500
18. SECURITY CLASSIFICATION OF THIS PAGE Unclassified
12

16. PRICE CODE

$\mathrm{AO} 3$

19. SECURITY CLASSIFICATION OF ABSTRACT Unclassified 